\title{
Mujeres mayores en el cine. Una evaluación de los proyectos fílmicos
}

\section{Elderly woman in films. An evaluation to the filmic projects}

Núm. 7 (2016), pp. 96-115

Pinazo Hernandis, Sacramento*1

Núñez-Domínguez, Trinidad ${ }^{*_{2}}$

Recibido: agosto, 2016 Aceptado: septiembre, 2016

JEL Clasif: Y9o

DOI: $10.5944 /$ reppp.7.2016.17068

\footnotetext{
*1 Sacramento Pinazo Hernandis. Profesora titular Psicología Social. Departamento de Psicologia Social. Universidad de Valencia. ORCID: http://orcid.org/oooo-0003-4364-4730 . E-mail: sacramento. pinazo@uv.es

*2 Trinidad Núñez-Domínguez. Profesora titular de Psicologia Social. Facultad de Comunicación. Universidad de Sevilla. Miembro de la Mesa de Ordenación e Impulso del Sector Audiovisual en Andalucía, dependiente del Instituto Andaluz de la Mujer. E-mail: mtnunez@us.es
} 


\title{
Resumen
}

La presencia de las mujeres en el cine tanto delante como detrás de la cámara es escasa; y esto ocurre más todavía en el caso de las mujeres mayores. Con una mirada de género desde la Gerontología hemos realizado una selección y posterior evaluación de las películas estrenadas entre 1960 y 2015 en las que el protagonismo o co-protagonismo fuese de una mujer mayor de 55 años, obteniendo un total de 63 películas. Con la información obtenida al utilizar una hoja de registro y análisis, se realizó un análisis de contenido que dio lugar a diferentes categorías temáticas y subcategorías. Los resultados muestran que son muy escasas las películas cuya trama argumental gira en torno a mujeres mayores. Las películas analizadas se clasificaron en tres categorías con sus diferentes subtemas: a. Mujeres tratadas en positivo (que se subdividen en mujeres autónomas, que gestionan el conflicto de una manera competente; mujeres con deseos de amistad, amor o de sexo; y finalmente, mujeres valientes, inconformistas, empoderamiento). b. Mujeres en su rol tradicional (cuidadoras, abnegadas y dependientes). c. Mujeres tratadas en negativo (subdivididas en suegras insoportables; brujas y perversas; y mujeres desquiciadas). El mayor número de películas corresponde a las categorías neutra y negativa. En conclusión, se necesitan mayores esfuerzos para educar la mirada del público e incorporar la perspectiva femenina y feminista detrás de la cámara. Si no es así, seguiremos perpetuando en el cine una visión de las mujeres mayores negativa, sesgada y alejada de la realidad actual.

Palabras clave: Evaluación; Proyectos fílmicos; Cine; identidad de género; mujeres mayores; Gerontología

\begin{abstract}
Woman on cinema both in front of and behind the camera is still limited; and this situation happens more frequently in the case of elderly women. We have selected and analysed films produced between 1960 and 2015 which leading role or co-protagonism was an elderly woman (up to 55 years), with a gender focus from Gerontology $(\mathrm{N}=63)$. We have done a content analysis bringing together similar films in thematic categories: a.Films with a storyline around elderly woman are scarce. b.Films evaluated have been grouped into three categories with different sub-categories: a positive perspective (autonomous, competent conflict management, explicit expression of desires, love and sex, courage, non conformity, empowerment); c.Women in a traditional role (caregivers, selfless and dependents). A negative perspective (unbearable mother-in-law, witches and perverses, and deranged). The largest number was for neutral and negative categories. In conclusion, a big effort is essential, educating people in observation and incorporating the perspective of woman and feminism behind cameras. If not, it will remain a social negative view of elderly, biased, far removed from any current and future reality.
\end{abstract}

Key Words: Evaluation; Filmic projects; Cinema; gender identity; elderly woman; Gerontology 


\section{Introducción}

Los Medios de Comunicación construyen y reconstruyen nuestras identidades influyendo en quiénes somos y en los rasgos que nos definen grupalmente, como dicen Garcia-Jimenez y Nuñez (2008). ¿Cómo se define nuestra identidad de mujeres conforme avanza el ciclo vital? ¿cómo somos representadas en los Medios de Comunicación?

Las mujeres mayores suelen ser invisibles como sujetos de análisis científico en los estudios realizados en los Medios de Comunicación. Maqueira (2002) denuncia las escasas investigaciones realizadas en castellano sobre mujeres mayores: «los sesgos androcéntricos se articulan de muy diversas maneras en el conocimiento y en la vida social y se inscriben de un modo prácticamente inconsciente en nuestra manera de proceder como consecuencia de una larga historia de infravaloración de las mujeres» (Maqueira, 2002: 19). No obstante es destacable la larga labor de Freixas (2008, 2013) en este área de estudio. Específicamente una de sus últimas obras que, con una intención de divulgación científica, ha sido capaz de llegar a la comunidad social con agilidad, sin perder profundidad en sus argumentos rompiendo prejuicios sexistas relacionados con la edad y subrayando que los factores sociopolíticos y económicos condicionan las maneras de entender la vejez.

Si nos centramos en trabajos y publicaciones relacionadas con el medio audiovisual, la falta de referencias a las mujeres mayores es especialmente notable. Gordillo (2010) y Gordillo y Guarinos (2010) reconocen que la vejez no es un tema de interés para el audiovisual y argumentan que parece no resultar agradable la estética de la persona mayor, quedando en evidencia el prejuicio sexista sobre los cánones de la belleza femenina conforme aumenta su edad. Como señaló Mulvey, el protagonista varón es el portador de la mirada y el personaje femenino es la cosa mirada. La seducción del personaje masculino pertenece al orden del relato y nace de su capacidad de ser el yo ideal. Mientras que las mujeres aparecen como personajes vicarios que carecen por sí mismas de entidad; su atractivo en el cine depende de su belleza corporal. A esas mismas conclusiones llegan los trabajos de Ramos y Papí (2012) al analizar la publicidad televisada.

En este sentido el trabajo de Neroni (2016) sobre las películas de la directora belga Agnés Varda es muy interesante. Agnés Varda recibió en el festival de Cannes de 2015 la Palma de Oro, premio honorífico a su trayectoria como directora de cine, erigiéndose como la primera mujer directora en recibir este premio. En la época contemporánea en que vivimos, la huella de la sociedad patriarcal sigue vigente y esto se aplica también en la industria del cine, en donde la mujer y su belleza son resaltadas. Autoras feministas como Varda han dedicado sus películas a hacer pensar a los espectadores sobre las cuestiones planteadas. Entre otros temas, en sus películas ha mostrado el antagonismo al que se enfrenta la mujer en la propia definición de femineidad: la mujer poderosa e independiente por un lado pero también la mujer sexy, dependiente y cuidadora de otros. Como la vida misma. Por ejemplo, en la película Cléo de 5 a 7 , pone a la mujer en el centro de la narrativa fílmica, analizando la relación de la belleza de la mujer con su identidad femenina. Siguiendo a Neroni (2016) la discusión de Varda gira en torno a cómo la Sociedad vincula la belleza con la biología, en el caso de las mujeres. Y esto está muy relacionado con la tesis de este artículo ċserá ésta una de las causas de la no inclusión de mujeres mayores en el cine? ¿La belleza de una mujer mayor no vende? 
En este artículo, el foco de análisis ha sido puesto en el cine. Se ha considerado pertinente utilizar como punto de partida la realización de una breve reflexión analíticoconceptual sobre el eje vertebrador de este texto: la presencia de las mujeres en el cine, tanto delante como detrás de la cámara. Una mirada de género desde la Gerontología. El cine es un importante vehículo para la difusión de ideologías, y nuestras creencias particulares se ven influidas por estas ideologías compartidas.

Usamos la perspectiva de género en el mismo sentido que le da Papí (2003: 137) porque «contribuye de lleno a la deconstrucción modernista y a la visión crítica de la ciencia moderna pero, sobre todo, hace emerger una realidad oculta, sexuada, al tiempo que enriquece la explicación de los fenómenos sociales proporcionando categorías y esquemas de análisis anteriormente no tenidos en cuenta.../...Los estudios de género, forman un todo del que emerge un enfoque propio, necesariamente transversal, que se entrecruza con otras disciplinas y las enriquece, dotándolas de un punto de vista reflexivo, crítico, que contribuye al conocimiento de la realidad, del objeto o sujeto de estudio».

Así, nos planteamos dos objetivos en este trabajo: 1. Realizar una revisión de las películas cuyo protagonismo o co-protagonismo sea de una mujer mayor y 2. Evaluar con un análisis del contenido las películas seleccionadas a partir de una hoja de registro, evaluando el modo en que las mujeres son representadas. Estos objetivo posibilitarán que se conteste a cuestiones como las siguientes: ¿Cómo presenta el cine a las mujeres mayores? ¿Se puede decir que el cine discrimina a las mujeres mayores? Y si es así, ¿̇en qué sentido?¿Qué propuestas se pueden hacer para promover buenas prácticas en la narración fílmica que incluyan a mujeres mayores?

\subsection{Las mujeres en los proyectos fílmicos: analizando la realidad}

Según el Catálogo de Cine Español del Ministerio de Educación, Cultura y Deporte ${ }^{1}$, en 2014 se estrenaron en España 67 largometrajes en salas comerciales; en 2015 fueron 72. Desagregando los datos por género, se comprueba que en 2014 fueron estrenadas 9 películas dirigidas por mujeres (lo cual representa un 13,43 \% del total de los estrenos) y en 2015 fueron estrenadas 10 (un 13,88 \%).

García-Prince (2003) o Fernández e Higueras (2010), se refieren a la existencia de guetos de terciopelo también en la industria cinematográfica española, definidos como uno de los matices del techo de cristal y subrayando que existen sectores laborales y profesionales que se feminizan, considerándose prejuiciosamente trabajos que parecen solo «aptos para mujeres». Si en Medicina, los varones ocupan, mayoritariamente la especialidad de cirugía y las mujeres las especialidades de pediatría, ginecología o medicina de familia (Pozzio, 2010; Arrizabalaga y Bruguera, 2009), en el caso del cine, las mujeres ocupan mayoritariamente puestos como el de peluquería, maquillaje o vestuario. Existen pocas especialistas, muchas menos guionistas que colegas varones, y en la dirección artística o técnica están, sobre todo, los varones (Silva, 2009).

En la investigación realizada por Arranz (2010) sobre las mujeres cineastas en España (2000-2006) la mayor parte de los filmes estaban protagonizados por varones (61,9 \%). La mayoría de las películas estaban dirigidas por varones (92,5 \%) lo

1 http://www.mecd.gob.es/dms/microsites/cultura/catalogodecine/2013/indices/Directores2013/ Directores2013.pdf

Revista de Evaluación de Programas y Políticas Públicas | Núm. 7 (2016), pp. 96-115 
que da como resultado un mundo de ficción distorsionado donde las mujeres están infrarrepresentadas. Los directores, tanto hombres como mujeres, tienden a hacer protagonistas de sus películas a personajes de su propio género y los hombres lo hacen en mayor medida que las mujeres. Este hecho ya había sido criticado por autoras estadounidenses como Lauzen y Dozier (1999) cuando demostraron que las series de televisión estadounidenses producidas por mujeres atribuyen a los personajes femeninos un empoderamiento basado en el lenguaje que utilizan de una forma más frecuente que las producidas por hombres.

De las películas analizadas por Arranz (2010), aquellas que habían sido dirigidas por varones y cuyas protagonistas fueron mujeres, en una la mujer era prostituta, en dos, asesinas, y en otras dos, locas, desequilibradas o enloquecidas por la dependencia emocional de su marido.

En ese mismo periodo 2000-2006 se estrenaron en España 318 películas, fruto del trabajo de 355 directores, de los cuales tan sólo 37 eran mujeres directoras, lo que supone una ratio de 10,4 \%. Arranz (2010) lo denomina el borrado de las mujeres.

La mayoría de las veces las mujeres directoras tratan los temas con sentido del humor, sensatez, y a menudo con un punto de rebeldía y valor. Para Núñez-Domínguez (2009: 124): «las mujeres que toman decisiones como realizadoras ponen una mirada diferente empezando por la elección del tema y de los personajes. Parece menos probable que una directora utilice a una mujer como objeto del discurso y a un hombre como sujeto». O como decía Carmí (2005), las mujeres directoras buscan nuevas formas de representación porque están hartas de verse mal representadas. Resulta muy interesante observar a quién se le concede protagonismo. Según Núñez-Domínguez (2009) entre 1999 y 2008 se produjeron 1256 películas, 83 de las cuales estuvieron dirigidas por mujeres (6.6\%). Analizando una a una las películas dirigidas por mujeres, la persona que aparece como primer/a protagonista es una mujer en el $60 \%$ de las ocasiones.

Haciendo un repaso por quienes han sido las personas premiadas en los Óscar de Hollywood y, específicamente, los que se dan dado a la Mejor Dirección, podemos comprobar que nunca en 82 ediciones lo había ganado una mujer hasta 2010 (Katrhyn Bigelow por Tierra hostil), y sólo en tres casos han conseguido estar nominadas: Lina Wertmüller, por su película Siete bellezas (1975); Jane Campion, directora de El Piano (1993) y Sofia Coppola por Lost in translation (2003). Es resaltable, también, la peruana Claudia Llosa que con La teta asustada consigue ser nominada en 2009 al Oscar a la Mejor película de habla no inglesa. Si hablamos de Premios Goya, tan solo 8 mujeres han sido premiadas como directoras en las 30 ediciones hasta la fecha (tres de ellas en 2016). Y en referencia al Premio Nacional de Cinematografía, que desde 1980 ha otorgado premios por ejemplo a Carlos Saura, Luis García Berlanga o Pedro Almodovar, tan solo ha otorgado una vez el premio a una mujer, en 2014: a Lola Salvador, en su calidad de guionista y productora, además de seis premios a actrices en otras ediciones.

Esto ocurre dentro y fuera de Europa. Tras consultar listados de quienes han accedido a la dirección largometrajes a través de diferentes sitios web ${ }^{2}$ y de los datos que ofrecen los respectivos Ministerios de Cultura, encontramos que en el cine italiano, pueden reconocerse hasta un total de 189 nombres de directores. De ellos, solo nueve son mujeres, lo entre otros. 
que supone un escaso 4,76 \%. En Francia, los datos nos llevan al 10,12 \% del total; de 326 personas en la dirección de cintas, 33 son mujeres.

El liderazgo y el poder de las mujeres debe abrirse camino en las pantallas porque conlleva un valor social tangible: las mujeres que toman decisiones como directoras/ realizadoras proponen en sus películas una perspectiva diferente ofreciendo matices a los temas expuestos y a los personajes. Es más probable que una directora utilice a una mujer como sujeto activo en la película. Unido a esto, Castejón (2004: 15) mantiene que: «Nunca ha existido el término 'cine de hombres', porque el cine de hombres es el cine universal, el que tiene un punto de vista y un marcado protagonismo masculino; no es necesaria la diferencia. Por eso resulta tan lógico que las pocas mujeres que llegan a dirigir películas huyan despavoridas de términos como el de "cine de mujeres», que resta valor a su trabajo de cara a la Sociedad» .

Las directoras buscan nuevas formas de mostrar en la pantalla la realidad de las mujeres en la Sociedad. Un ejemplo de ello lo tenemos en el cine argentino. Las mujeres que entran en la dirección cinematográfica a finales de los noventa en Argentina nacieron entre la dictadura y la democracia, con valores que ponían en discusión la estructura existente, con interés por dar una significación distinta al lugar que ocupaban las hijas, esposas y madres. Lucrecia Martel Albertina Carri, Anahí Berneri, Vera Fogwill, Verónica Chem, Celina Murga, Sandra Gugliotta o Lucía Puenzo, son referentes en este sentido.

Es cierto que en algunos casos son las propias mujeres las que se «autocensuran", se imponen normas a la hora de acceder a la dirección de películas. Este sentido autocrítico está en la base de lo que se ha denominado en la literatura como techo de cemento (Chinchilla y León, 2004; Núñez-Domínguez, Estebaranz, Mingorance, Loscertales y Barcia, 2007), entendido como uno de los matices del techo de cristal y se convierte en un efecto secundario de uno de los estereotipos prejuiciosos que recaen sobre las mujeres: pueden salir al mundo público siempre que no abandonen el mundo privado que es el que les corresponde «naturalmente». Esta perversa creencia asumida y trabada en el imaginario colectivo es paralizante, aunque también es auto-protectora. El matiz negativo está en entender como algo normal y aceptable tener múltiples responsabilidades. Porque ello puede tener consecuencias no deseables a nivel psicosocial como, por ejemplo, llegar antes que cualquier varón a sentir agotamiento o estrés.

Diferentes investigaciones indican que las mujeres se han acostumbrado a una alta autoexigencia personal y profesional viviendo con sentimientos de culpa los posibles errores (Coria, 2003). Autoras como Arango (1998) o Delfino (2005) subrayan que el estado civil, la edad y la situación reproductiva son elementos de relevancia para las trayectorias profesionales de las mujeres. Se llega a observar una alta proporción de solteras y divorciadas entre las que desempeñan cargos directivos y, a la vez, un bajo número de mujeres en dichos cargos que son a la vez, madres. Estos mismos argumentos, e incluso amplificados, están detrás de muchas mujeres que, aun teniendo cualidades técnicas e ideas creativas, postergan sus proyectos audiovisuales o no los acometen, lo cual nos permite introducir otro término: el de piso o suelo pegajoso en el sector cinematográfico, que ha sido explicado de manera muy clara por Chodorow (2000) o Burín (1996), refiriéndose a aquellos factores que afectan a las mujeres que, teniendo poder de decisión en su ámbito laboral, son superadas por sus propios sentimientos de culpa influidos por la norma social, al entender que rompen los códigos exigidos a las «mujeres de verdad» 
(como son, por ejemplo, ser buenas madres y buenas esposas). El suelo pegajoso termina marcando el techo de cemento y afectando de manera determinante a las mujeres que trabajan en este sector.

¿Cuál es la identidad de las mujeres mayores que se transmite en el cine? ¿Qué se espera de ellas? Siguiendo a Sampedro (2004): hay identidades individuales, relacionadas con la trayectoria vital y que son negociadas mediante procesos interpersonales y mediáticos y en combinación con estilos de vida; y también existen identidades colectivas en las que pesa fundamentalmente la pertenencia a un grupo. ¿Representa el cine a mujeres mayores con poder, líderes? ¿Representa el cine a mujeres con autonomía económica y moral? ¿Representa el cine una ficción o representa la realidad?

\subsection{Las mujeres en la ficción cinematográfica. Mujeres mayores actrices}

Las cifras son decepcionantes teniendo las mujeres un difícil acceso a esa parte que se considera con alto prestigio profesional como es la dirección técnica, aunque también cuenta con serios problemas en otras áreas laborales dentro de la industria cinematográfica. La situación es suficientemente alarmante como para que muchas mujeres de este sector profesional se muestren abiertamente reivindicativas. Patricia Arquette, Oscar a la Mejor Actriz Secundaria, 2015, en su discurso al recoger el Premio afirmó que «Ya es hora de que tengamos, de una vez por todas, el mismo salario (que los hombres) y los mismos derechos» ${ }^{3}$.

Existe, además, una doble discriminación que entendemos como los efectos combinados de prácticas disfuncionales con base en la edad y el género. Especialmente las mujeres mayores tienen serios problemas para obtener papeles como actrices (y mucho más como actrices principales) y para acceder a algunos puestos laborales técnicos como, por ejemplo, guionistas. Con esta premisa, la actriz estadounidense Meryl Streep ha puesto en marcha el proyecto Writers Lab en marzo de 2015, con el objetivo de incrementar las oportunidades laborales para las guionistas de más de cuarenta años, con un curso de capacitación y la posibilidad de desarrollar los trabajos, dirigidos por directoras de renombre internacional. La iniciativa liderada por ella está también avalada por la organización Mujeres de Nueva York del Cine y la Televisión y el grupo de cineastas femeninas IRIS.

Diferentes investigaciones suscriben la existencia de esta doble discriminación citada. García-González (2009) afirma que: «También la edad está restringida en esos modelos, sobre todo para las mujeres. Son pocas las películas con protagonismo femenino de una mujer que supere los cuarenta años» (García-González, 2009: 66).

\section{Material y método}

Se realizó una búsqueda de películas en las bases de datos de cine más conocidas ${ }^{4}$ completada con páginas dedicadas a la crítica de cine ${ }^{5}$. Además, se revisó la información sistematizada sobre personas mayores en el cine ya elaborada por Pinazo-Hernandis (2013) Los criterios de selección de proyectos fílmicos fueron: la presencia de mujeres

$3 \quad$ Acto de entrega en los Premios Óscar en la edición de 2015.

4 www.imdb.com y www.filmotech.com

$5 \quad$ www.filmin.es y www.filmaffinity.com

Revista de Evaluación de Programas y Políticas Públicas | Núm. 7 (2016), pp. 96-115 
mayores de 55 años; ser películas estrenadas en España y proyectadas en salas comerciales; haber sido estrenadas entre 1960 y 2015.

Es imposible conocer todo lo que se estrena cada año, pues hay filmes que apenas se promocionan, otros que exclusivamente se estrenan en las grandes ciudades, muchas de las películas realizadas cada año no llegan a nuestras pantallas y algunas no lo harán nunca. Hay grandes realizadores que son ninguneados en los cines españoles, otros que no resultan comerciales. Por esta razón se buscó en la sinopsis de las películas de las bases de datos revisadas, a partir de las palabras clave «mujer», «años», «anciano/a», «mediana edad», «jubilado/a», «residencia/asilo/hogar de ancianos», «suegra», «abuela/o/os», y se realizó un cribado manual hasta llegar a la selección de 63 películas, sabiendo que es posible que nos hayamos dejado muchas sin revisar; nuestra pretensión no era la exhaustividad sino analizar las películas seleccionadas. Para la evaluación se aplicó una ficha de análisis de contenido elaborada por tres expertos en cine y en Gerontología que permitió agrupar dichas películas en categorías temáticas e hizo aflorar los subtemas o subcategorías. Dejamos fuera algunas películas en las que aparecen mujeres mayores de 55 años pero que no han sido estrenadas en España en salas comerciales como Lovely Louise (dir. Bettina Oberli, 2013) que solo ha sido exhibida en alemán, o Grandma (dir. Paul Weitz, 2015) en inglés.

En la ficha de análisis se registraron, además del título, año, país, director/a; el tema principal sobre el que trata la película; la presencia o no de mujeres en papel protagonista, co-protagonista, o papel trascendente en la trama narrativa no protagonista; el modo cómo se muestra a las mujeres mayores de 55 años: positivo, negativo, y tradicional (que no neutro).

Cada película fue evaluada individualmente con la ficha de análisis por cada uno de los tres investigadores y después se realizó una puesta en común para valorar los acuerdos o discrepancias y otorgar el valor final a cada film. El ahondar en cada una de las películas permitió conocer el porcentaje de directoras/directores que abordan la temática de la vejez y eligen a una mujer mayor como protagonista de la historia e incluso la nacionalidad de dichas películas. Por último, se visionó de nuevo una tercera parte de las películas seleccionadas del listado $(\mathrm{N}=22)$ para poder realizar una reflexión detallada sobre su contenido.

Se han recopilado 63 películas en las que las mujeres mayores de 55 años tienen alta relevancia bien por ser protagonistas, co-protagonistas o por tener adjudicado un papel trascendente en la trama narrativa, siendo sujetos (personaje con trayectoria) y no objetos explícitos de la narración fílmica. Los subtemas o subcategorías afloraron tras el análisis de contenido de cada film (Ver tabla 1).

Es importante destacar que más del $80 \%$ de dichas películas se han estrenado entre los años 2000 y 2015 .

Como criterio de selección y por consenso, definimos como "protagonista» al personaje cuyo experiencia o periplo se narra, que suele ser el que más tiempo ocupa la pantalla, que sirve de hilo conductor y centro neurálgico del relato y de conexión entre los demás personajes, que centra la trama y el dispositivo cinematográfico y el que emocionalmente más importa a los espectadores. 


\section{Resultados}

\subsection{Análisis descriptivo}

Se obtuvieron 63 películas que cumplían los criterios de inclusión. Con respecto a la dirección y desagregando por sexos, de las 63 películas en las que aparecen mujeres de 55 años como protagonistas, tan solo 12 han sido dirigidas por mujeres (19.35\%), siendo 4 de ellas producidas en España y 3 en EEUU. Entre los temas de estas doce películas aparece a menudo la llegada de la enfermedad (Alzheimer, amnesia), la reflexión sobre la amistad, el amor, las relaciones de pareja, el autodescubrimiento, la aceptación y el empoderamiento.

Con respecto al lugar donde se han producido las películas, ha sido en el viejo continente en un $62.2 \%$ de los casos ( $\mathrm{N}=38$ películas), destacando España (14) y Reino Unido (10). Son norteamericanas 13 de ellas (20.63\%). En las de producción latinoamericana ( $\mathrm{N}=10,16.1 \%$ ) sobresale significativamente Argentina (con 8 películas, una de ellas con coproducción española). Es importante mencionar las 2 películas asiáticas (3.2 \% de la muestra), una de Corea y otra de Israel, y una película de Filipinas (con coproducción francesa).

Las películas españolas con protagonistas o co-protagonistas mujeres han sido dirigidas por hombres en 8 ocasiones y por mujeres en 3; si bien hay que decir que Isabel Coixet, directora nacida y nacionalizada española, dirige una película de EEUU en 2014 y por tanto, no aparece contemplada entre las películas españolas (Ver tabla 1 en la siguiente página). 
Tabla I. Listado de proyectos fílmicos (largometrajes) con protagonismo (o co-protagonismo) de mujeres mayores

\begin{tabular}{|c|c|c|c|c|c|}
\hline Núm. & Título & Año & País & Nombre directorla & Género \\
\hline 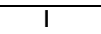 & Agosto & 2013 & EEUU & John Wells & Varón \\
\hline 2 & Amour & 2012 & Austria/Francia & Michael Haneke & Varón \\
\hline 3 & Antonia & 1995 & Holanda & Marleen Gorris & Mujer \\
\hline 4 & Aprendiendo a conducir & 2015 & EEUU & Isabel Coixet & Mujer \\
\hline 5 & Atlas de geografía humana & 2007 & España & Azucena Rodriguez & Mujer \\
\hline 6 & Cándida & 2006 & España & Guillermo Fesser & Varón \\
\hline 7 & Carmina o revienta & 2012 & España & Paco León & Varón \\
\hline 8 & Carmina y amén & 2014 & España & Paco León & Varón \\
\hline 9 & Conversaciones con mamá & 2004 & Argentina & Carlos Oves & Varón \\
\hline 10 & Corazón silencioso & 2014 & Dinamarca & Bille Augusts & Varón \\
\hline II & Cuando menos te lo esperas & 2003 & EEUU & Nancy Meyers & Mujer \\
\hline 12 & Cleopatra & 2011 & Argentina/España & Eduardo Mignona & Varón \\
\hline 13 & El exótico hotel Marigold & 2011 & EEUU & John Madden & Varón \\
\hline 14 & El hijo de la novia & 2001 & Argentina & Juan Jose Campanella & Varón \\
\hline 15 & El nido vacío & 2008 & Argentina & Daniel Burman & Varón \\
\hline 16 & Elsa y Fred & 2005 & Argentina & Marco Carnevale & Varón \\
\hline 17 & En el estanque dorado & 1998 & EEUU & Mark Rydell & Varón \\
\hline 18 & Es complicado & 2010 & EEUU & Nancy Meyers & Mujer \\
\hline 19 & Espias desde el cielo & 2015 & Reino Unido & Gavin Hood & Varón \\
\hline 20 & Fédora & 1978 & Francia & Billy Wilder & Varón \\
\hline 21 & Función de noche & 1981 & España & Josefina Molina & Mujer \\
\hline 22 & Ginger y Fred & 1985 & Italia & Federico Fellini & Varón \\
\hline 23 & Gloria & 2013 & Chile & Sebastian Lelio & Varón \\
\hline 24 & Historias mínimas & 2002 & Argentina & Carlos Sorín & Varón \\
\hline 25 & Into the Woods & 2015 & EEUU & Rob Marshall & Varón \\
\hline 26 & Iris & 2002 & Reino Unido & Richard Eyre & Varón \\
\hline 27 & La casa de mi abuela & 2006 & España & Adán Aliaga & Varón \\
\hline 28 & La caja de Pandora & 2008 & Alemania & Yesim Ustaoglu & Mujer \\
\hline 29 & La madre del novio & 2005 & EEUU & Robert Luketi & Varón \\
\hline 30 & La once & 2014 & Chile & Maite Alberdi & Mujer \\
\hline 31 & La primavera romana de la Sra Stone & 1961 & Reino Unido & Jose Quintero & Varón \\
\hline 32 & La vida empieza hoy & 2009 & España & Laura Mañá & Mujer \\
\hline 33 & La vieja de atrás & 2010 & Argentina & Pablo José Meza & Varón \\
\hline 34 & Las ballenas de agosto & 1987 & Reino Unido & Lindsay Anderson & Varón \\
\hline 35 & Las chicas de la lencería & 2006 & Suiza & Bettina Oberli & Mujer \\
\hline 36 & Las chicas del calendario & 2003 & Reino Unido & Nigel Cole & Varón \\
\hline 37 & Las horas del verano & 2008 & Francia & Oliver Assayas & Varón \\
\hline 38 & Las manos de mi madre & 2013 & España & Mireia Gabilondo & Mujer \\
\hline 39 & Lejos de ella & 2006 & Canadá & Sarah Polley & Mujer \\
\hline 40 & Lola & 2009 & Francia/Filipinas & Brillante Mendoza & Varón \\
\hline 41 & Los limoneros & 2008 & Israel & Eran Riklis & Varón \\
\hline 42 & Lugares comunes & 2002 & Argentina & Adolfo Aristaín & Varón \\
\hline 43 & Mamá cumple 100 años & 1979 & España & Carlos Saura & Varón \\
\hline 44 & Mis tardes con Margueritte & 2009 & Francia & Jean Becker & Varón \\
\hline 45 & Nacidas para sufrir & 2009 & España & Miguel Albaladejo & Varón \\
\hline 46 & Paseando a Miss Daisy & 1989 & EEUU & Bruce Beresford & Varón \\
\hline 47 & Philomena & 2013 & Reino Unido & Stephen Frears & Varón \\
\hline 48 & Poesía & 2003 & Corea del Sur & Lee Chang-Dong & Varón \\
\hline 49 & Saraband & 2003 & Suecia & Ingmar Bergman & Varón \\
\hline 50 & Solas & 2000 & España & Benito Zambrano & Varón \\
\hline 51 & Si de verdad me quieres & 2012 & EEUU & David Frankel & Varón \\
\hline 52 & Siempre Alice & 2014 & EEUU & Richard Glatzer & Varón \\
\hline 53 & The mother & 2003 & Reino Unido & Roger Michel & Varón \\
\hline 54 & Tomates verdes fritos & 1991 & EEUU & Jon Avnet & Varón \\
\hline 55 & Tres veces 20 años & 2011 & Francia & Julie Gravas & Mujer \\
\hline 56 & Una canción para Marion & 2013 & Reino Unido & Paul Williams & Varón \\
\hline 57 & Una dama digna & 2008 & Reino Unido & Dan Ireland & Varón \\
\hline 58 & Una dama en París & 2012 & Francia & Ilmar Raag & Varón \\
\hline 59 & ¿Por qué se frotan las patitas? & 2006 & España & Alvaro Begines & Varón \\
\hline 60 & ¿Qué hacemos con la abuela? & 1990 & Francia & Étienne Chatilliez & Varón \\
\hline 61 & ¿Y si vivimos todos juntos? & 2011 & EEUU & Stéphane Robelin & Varón \\
\hline 62 & 80 egunean & 2010 & España & Jose M Goenaga y Jon Garaño & Varón \\
\hline 63 & 45 años & 2015 & Reino Unido & Andrew Haigh & Varón \\
\hline
\end{tabular}

Fuente: elaboración propia. 
La selección de películas permitió una clasificación en tres grandes bloques con sus diferentes subtemas:

a) Mujeres tratadas en positivo, destacándose su autonomía moral o la explicitación de deseos e intereses. Los subtemas que aparecen en esta categoría son: autonomía de decisión; gestión del conflicto de una manera competente; expresión de deseos de amistad, de amor o de sexo; valentía, inconformismo, empoderamiento e iniciativa.

b) Mujeres en su rol tradicional (que no neutro), que representan unos roles y rasgos esperables, aquellos que se mantienen en el tiempo sobre lo que supone ser una «buena» mujer (abnegada, dependiente, cuidadora). En esta categoría encontramos los subtemas que hemos denominado: cuidadoras, abnegadas y dependientes.

c) Mujeres tratadas en negativo, que dan miedo, reproduciendo un rol de mujeres que no promueven el «ser modelo de referencia» para nadie y que son representadas como insolidarias o insoportables (esa idea de «histérica» está presente). Dentro de esta categoría aparecen los subtemas: suegras insoportables; perversas, brujas e insolidarias; desquiciadas y locas.

Somos conscientes de que algunas películas podrían enmarcarse en dos categorías o subcategorías (por ejemplo, «que gestionan el conflicto de una manera competente», «valientes/inconformistas/con iniciativa» y a la vez «dependientes», viviendo en una residencia de personas mayores, como la co-protagonista de Tomates Verdes Fritos (Jessica Tandy). También sabemos que nos dejamos otras películas en donde aparecen mujeres mayores pero no con papel de protagonista sino en un papel coral. En Into the Woods, el papel de actriz de reparto de Meryl Streep es fundamental para la trama, pero los protagonistas son la niña, un panadero y su esposa. En este caso, Meryl Streep hace un papel de bruja mala malísima.

En el listado que aparece en la tabla 2 se pueden ver las categorías y los subtemas emergidos tras el análisis y se muestra algún ejemplo de película $(\mathrm{N}=22)$, para cada una de ellas (Ver tabla 2 en la siguiente página). 
Tabla 2. Clasificación de los proyectos fílmicos en categorías temáticas y subtemas.

\begin{tabular}{|c|c|c|}
\hline Temas & Subtemas/subcategorías & Ejemplos \\
\hline \multirow{15}{*}{$\begin{array}{l}\text { Mujeres } \\
\text { tratadas en } \\
\text { positivo }\end{array}$} & \multirow{2}{*}{$\begin{array}{l}\text { Autónomas económicamente } \\
\text { y en toma de decisiones }\end{array}$} & Atlas de geografia humana (2007) \\
\hline & & Gloria (2013) \\
\hline & \multirow{3}{*}{$\begin{array}{l}\text { Gestionan el conflicto de una } \\
\text { manera competente }\end{array}$} & Carmina y revienta (2013) \\
\hline & & Carmina y amén (20I4) \\
\hline & & Los limoneros (2008) \\
\hline & \multirow{4}{*}{$\begin{array}{l}\text { Con deseos de amistad, de } \\
\text { amor o de sexo }\end{array}$} & La vida empieza hoy (2013) \\
\hline & & 80 egunean $(2010)$ \\
\hline & & ¿Por qué se frotan las patitas? (2006) \\
\hline & & Elsa y Fred (2005) \\
\hline & \multirow{6}{*}{$\begin{array}{l}\text { Valientes/inconformistas/con } \\
\text { iniciativa/con poder }\end{array}$} & Philomena (2014) \\
\hline & & Una canción para Marion (20/3) \\
\hline & & Las chicas de la lencería (2006) \\
\hline & & Aprendiendo a conducir (2015) \\
\hline & & Tomates verdes fritos (1991) \\
\hline & & Espías desde el cielo (2015) \\
\hline \multirow{3}{*}{$\begin{array}{l}\text { Mujeres en su } \\
\text { rol tradicional } \\
\text { (que no neutro) }\end{array}$} & Cuidadoras & Solas (1999) \\
\hline & Abnegadas & Función de noche (198I) \\
\hline & Dependientes & $\begin{array}{l}\text { La caja de Pandora (2008) } \\
\text { Amour (20I2) }\end{array}$ \\
\hline \multirow{3}{*}{$\begin{array}{l}\text { Mujeres } \\
\text { tratadas en } \\
\text { negativo }\end{array}$} & Suegras insoportables & La madre del novio (2005) \\
\hline & Perversas/brujas/insolidarias & $\begin{array}{l}\text { The mother (2003) } \\
\text { Into the Woods (2014) }\end{array}$ \\
\hline & Desquiciadas/locas & Agosto (20|3) \\
\hline
\end{tabular}

Fuente: elaboración propia. 


\subsection{Análisis narrativo}

Son escasas las películas cuya trama argumental gira en torno a mujeres mayores. Observamos que cuando son las mujeres las protagonistas de los proyectos fílmicos, su presencia no lo es de manera exclusiva; el volumen más amplio de las películas que aparecen en el listado responden a co-protagonismos o protagonismos corales (2 de cada 3 , lo que supone un $75 \%$ ). En general, las mujeres no suelen aparecer como sujetos centrales del discurso fílmico tal y como ya apuntaba Arranz (2010) y la edad, además, se convierte en una barrera añadida para las mujeres. Ser actriz mayor reduce las opciones laborales.

Ahondando en el análisis narrativo, se ha encontrado un bloque de películas donde las mujeres mayores son tratadas "con simpatía», esto es, en positivo. Es la categoría con menor número de películas. En la primera subcategoría, «mujeres autónomas», la película Atlas de geografía humana plantea la historia de cuatro mujeres, y dos de ellas que trabajan en un departamento editorial superan los cincuenta años. La película narra sus historias personales y cómo están redefiniendo sus vidas. Gloria (Paulina García), muestra a una mujer independiente económicamente, con deseos de sexo y que termina siendo capaz de desmontar su propia dependencia emocional para plantearse relaciones interdependientes. La escena final está llena de simbolismos que refuerzan esta idea: Gloria se quita las gafas y se pone a bailar sola, rechazando la invitación de un hombre para el baile. Y eso la hace feliz; se da cuenta de que no necesita a nadie, tan solo necesita quererse a sí misma. Sorprendentemente en el interesante thriller Espías desde el cielo (Helen Mirren) la protagonista no tiene el papel de abuela ni de suegra: es una oficial de la inteligencia militar británica que lidera una operación secreta para capturar a un grupo de terroristas en Kenia.

Una segunda subcategoría, corresponde a las «mujeres que muestran sus deseos abiertamente». Por ejemplo, en la película La vida empieza hoy, se muestra la evolución del personaje principal (Pilar Bardem): de una mujer adaptada al rol tradicional de esposa a una mujer que quiere cambiar, con deseos de aprender, de cuidar su cuerpo, con deseos de sexo y de disponer de autonomía moral. Pocas veces tratan las películas sobre el deseo sexual de las mujeres. Incluso en el caso del cine pornográfico, y a pesar de que trabajen mujeres en él, son cintas realizadas para consumo de varones. Además, cuando el sexo se convierte en argumento, son las mujeres jóvenes las que lo protagonizan. Es el caso de la película francesa La vida de Adèle o la cinta canadiense Sleeping Beauty. Posiblemente esté relacionado con las afirmaciones de las profesoras Gordillo y Guarinos (2010) vinculando a argumentos estéticos el que no se enseñen cuerpos con arrugas o cuerpos que no cumplen los parámetros normalizados de belleza. Por ese motivo se deben destacar varias películas más además de las anteriormente nombradas. Por ejemplo, en ¿Por qué se frotan las patitas? Aunque es una historia familiar, el papel de la abuela (Lola Herrera) es disonante, y por ello significativo: María está cansada de ser considerada solo abuela y reivindica ser mujer. Existe un momento donde se la «sorprende» en la cama con su novio. Eso sí, la familia cuando entra en la casa piensa que se la van a encontrar muerta y que era esa la razón de que no respondiese a las llamadas. En Elsa y Fred se muestra a una pareja octogenaria (ella, China Zorrilla) interesada no solo en hacerse compañía sino en mantener su sexualidad activa. La película 80 egunean (Itziar Aizpuru y Mariasun Pagoaga) permite que se analice una triple discriminación: 
ser mujer, ser mayor y ser lesbiana. Como decía Sampedro (2004), la identidad femenina hegemónica aún sigue definida, en gran parte, por su capacidad de despertar el deseo del varón. Las escasas películas que tienen a una mujer lesbiana como protagonista se destinan a mercados reducidos (el «cine de gays y lesbianas») o poco legitimados (la pornografía).

La película es un ejemplo para la reflexión de lo que significa la interseccionalidad, esto es, la interacción simultánea de las diversas discriminaciones que puede padecer una persona y que configuran su identidad, y que no equivale a la suma de todas las causas de discriminación sino más bien a la interacción de éstas en cada persona o grupo social, reflejando las diferentes estructuras de poder existente en la sociedad misma (Crenshaw, 1989; Lombardo y Verloo, 2010).

En esa visión positiva se encuadran las películas de la subcategoría tercera, referida a las «mujeres que gestionan el conflicto de una manera muy competente» como la historia de Carmina Barrios (en Carmina o revienta y en Carmina y amén). Ambas películas presentan a una mujer de unos sesenta años (Carmina Barrios), con pocos estudios pero con mucha competencia social para gestionar problemas cotidianos de su mundo laboral y de su entorno familiar. En Los limoneros se muestra una viuda palestina (Hiam Abbass) que defiende su huerto ante su vecino, un político israelí de manera tenaz; con objetivos claros: conservar lo que le corresponde por derecho.

Una cuarta subcategoría es la de las «mujeres valientes, inconformistas, empoderadas, emprendedoras y con iniciativa». En Las chicas de la lencería se demuestra que nunca es tarde para comenzar nuevos proyectos en la vida. En la película se plantea un tema poco tratado en la narrativa cinematográfica: la alianza entre mujeres. La amistad entre personas del mismo sexo, lo que algunos trabajos han denominado como homosociabilidad (Foster, 2001), ha estado prácticamente reservada a los hombres y es definido como un principio del patriarcado heterosexista encargado de fomentar la solidaridad entre hombres en defensa de una sociedad masculina en la que las mujeres sirven, sobre todo, para confirmar la relación entre ellos. Arranz (2015) denuncia que en el cine en general no se proyecta la alianza entre mujeres y que cuando se produce esa relación se reduce al ámbito familiar: madres-hijas o hermanas. En cambio, sí se proyecta con cierta frecuencia una relación basada en la rivalidad; algo que favorece la idea prejuiciosa de que el trabajo en equipo entre mujeres es imposible. Esta misma amistad entre mujeres se muestra espléndidamente en La Once (2014), que muestra los encuentros mensuales de cinco mujeres que se reúnen a tomar té desde hace sesenta años y hablan, discuten, tienen confidencias...

Marcela Lagarde es quien en 1989 pone el énfasis en la importancia del hermanamiento (la alianza) entre las mujeres e introduce en su discurso la palabra sororidad, un término que nombra ese pacto simbólico que firman muchas mujeres para contrarrestar la brecha social existente defendiendo que, aunque naturalmente se entrena a los hombres para aliarse, las mujeres pueden hacerlo, obteniéndose resultados que se cristalizan en proyectos comunes más pertinentes y más potentes. La sororidad va más allá de lo que propone el concepto de solidaridad; implica no solo compartir ideas o formas de ver la vida sino el apoyo y el reconocimiento incluso desde la divergencia en la forma de entender y evaluar ideas y creencias. Ejemplos claros aparecen en cintas como Las chicas de la Lencería, La Once, 80 egunean, Tomates verdes fritos o Las chicas del calendario. 
Cuando se hace un análisis pormenorizado de los protagonismos de las películas, en algunos casos encontramos que la mujer es la dueña del discurso solo en apariencia porque la historia está vehiculizada por el varón, que es quien articula el relato. Este es el caso, por ejemplo, de la película Philomena, donde se plantean dos vidas en paralelo: la historia de Philomena (Judi Dench) y la de un periodista que es «quien destapa» la situación de ella, pudiéndose adjudicar el papel del héroe real. Lo encontramos de una manera muy parecida en la película Una canción para Marion. Aunque ya en el título aparece ella, una mujer mayor enferma de cáncer en sus últimas semanas de vida (Vanessa Redgrave), el foco está puesto en el marido de Marion, hombre atormentado, triste, incapaz de mostrar sus sentimientos; pareciendo que el centro del discurso narrativo es él porque es quien necesita cambiar de actitud y quien termina resultando el sujeto del cambio. También en Amour la protagonista es ella, una octogenaria que ha sufrido una hemiplejia, obteniendo además la nominación al Oscar a la mejor actriz en 2013, pero el foco se pone en él, el cuidador, el que sufre la pérdida, el que no puede soportar la carga del cuidado. Por ejemplo, en El Hijo de la Novia los protagonistas son dos varones (Ricardo Darín y Héctor Alterio) y el papel de «la novia» es el de una mujer dependiente, en este caso con Alzheimer (Norma Aleandro). Igualmente ocurre en ¿Por qué se frotan las patitas? Quien vertebra la historia es Luis, que es abandonado por las mujeres de su familia (su hija, su madre, su pareja), quedando simbólicamente resaltado que «a las mujeres no hay quien las entienda».

La segunda categoría recoge las películas en las que aparecen «mujeres que se ajustan al rol tradicional (no neutras)». Aquí encontramos subcategorías como la de «cuidadoras», por ejemplo en la película Solas, Rosa (María Galiana) es retraída; se conforma con la vida que le ha tocado vivir (una vida junto a un hombre violento e intolerante) donde se incluye como algo natural cuidar de otras personas. Rosa agradece la atención que le prestan las personas que la rodean, aunque sean mínimas y tiene una autoestima descuidada (no se ha parado nunca a pensar qué es lo que quiere y espera de la vida). La subcategoría de «abnegadas» la vemos en Función de noche que «plantea a una mujer en clara encrucijada por definir su identidad y lucha por su libertad» (Castejón, 2004: 315), no deja de mostrarse, aunque parezca contradictorio, a una mujer que ha renunciado a tener iniciativa e intereses. La tercera subcategoría es la de «mujeres dependientes» emocionalmente de los hombres o físicamente por necesitar cuidados. Lo vemos en $L a$ Caja de Pandora y en Amour, por ejemplo. En Amour se cuenta la historia de Anne y Georges. Anne (Emmanuelle Riva) después de una operación quirúrgica queda con una hemiplejia y es su marido quien la tiene que cuidar. El film muestra a una mujer cada vez más dependiente conforme avanza la enfermedad.

Una tercera categoría es la que presenta a las mujeres de modo negativo, como «mujeres que dan miedo» En estos casos, y de manera permanente y explícita, se presentan personajes que responden al estereotipo que aparece en la subcategoría primera, «suegra insoportable», manipuladora y egoísta, como en La madre del novio (Jane Fonda); en la subcategoría segunda «brujas, malas» como en Into the Woods; o en la subcategoría tercera "desquiciadas, locas», madres mostradas como habiendo perdido el control de su vida e «ingobernables» aunque sus familias intenten poner orden en las relaciones interpersonales, como ocurre en Agosto (Meryl Streep). Se presenta un número interesante de películas que muestran a mujeres que se ajustan a ese rol perverso con el que a menudo aparece la mujer mayor retratada, también en los cuentos infantiles. 


\section{Conclusiones}

La evaluación de las películas cuyo protagonismo o co-protagonismo es de una mujer mayor, ha mostrado un número pequeño de películas comparado con el número de estrenos de cada año. Teniendo en cuenta los criterios de inclusión analizamos 63 películas. Con respecto a la dirección y desagregando por sexos, de las películas en las que aparecen mujeres de 55 años como protagonistas, tan solo 12 han sido dirigidas por mujeres. Analizando la dirección de las películas y desagregando resultados por continentes y género, la mayor parte de esas películas han sido producciones europeas, españolas o británicas, seguido de las norteamericanas. Existe una reivindicación vinculada al género de quien dirige una película. Algunas directoras se han quejado de esa idea instalada en el imaginario colectivo de que una película protagonizada por mujeres es mejor entendida por las mujeres frente una película protagonizada por hombres donde cualquier persona puede identificarse con el protagonista varón. Parece que es más fácil que una mujer exprese abiertamente que le gusta Pulp Fiction a que un varón diga lo propio sobre Thelma y Louis. En paralelo, son ya algunos trabajos los que tienen como reflexión de base desmontar la idea de que el cine que hacen las mujeres es solo para mujeres frente al cine que hacen los hombres que está hecho para todos los públicos. Hablar de cine de mujeres o cine para mujeres parece conllevar de modo implícito un matiz peyorativo. Esta es una cuestión a revertir por injusta y por irreal.

Hay que tener en cuenta el poder socializador del cine reforzando creencias previas, ofreciendo visiones del mundo, determinando las percepciones de la realidad y ayudando a reconstruirla (Morduchowicz, Marcon y Minzi, 2004; Martínez-Salanova, 2003; Pinazo-Hernandis, 2013). Como mantiene Aguilar (2015: 138): «Nuestra mente, nuestras emociones, nuestro imaginario (no solo nuestra ideología) se construyen con los materiales que la cultura nos aporta». La autora afirma, además, que «lo que importa en el relato no es que sea verdad o mentira sino el potencial que tenga para crear realidad en nosotros. Su capacidad para modular nuestro propio relato personal, para dejarnos huellas mnémicas, emocionales, interpretativas» (Aguilar, 2015: 142). Atendiendo a la revisión realizada, consideramos que en el tratamiento de mujeres mayores el cine aún queda mucho por hacer. La incorporación de la perspectiva femenina y feminista detrás de las cámaras, asumiendo guión/dirección, seguramente contribuirá a desmontar prejuicios sexistas.

Al comienzo del artículo nos planteábamos la pregunta ¿Cómo presenta el cine a las mujeres mayores? El análisis del contenido de las películas evaluando el modo en que las mujeres son representadas ha mostrado que en la mayoría de los casos están muy sujetas a roles y rasgos tradicionales y esperables. Se las presenta demasiadas veces como dependientes e inmaduras o manipuladoras y egoístas, sin iniciativa y poder. De manera simbólica o explícita se refuerzan una vez tras otra los prejuicios vinculados a ser mujer y mayor.

¿Qué propuestas se pueden hacer para promover buenas prácticas en los proyectos fílmicos que incluyan a mujeres mayores? Pensamos que además de los papeles de bruja, enferma, abuela, suegra o solterona cotilla, las mujeres mayores pueden aparecer en muchos y diferentes papeles como lo hacen los varones. Nos llama la atención y nos alegra haber visto películas como Espías desde el cielo, thriller bélico en donde Helen Mirren, septuagenaria, encarna a una oficial de la inteligencia militar británica que lidera una operación secreta. 
No se trata tanto de exigir un cambio en la perspectiva de quien narra historias en el cine, aunque no es esa una cuestión menor; más bien lo que solicitamos es un esfuerzo mayor en educar la mirada de quienes acceden a estos productos. Con formación adecuada sobre los efectos perversos de estereotipos y prejuicios, la ciudadanía estará en mejores condiciones de desmontarlos y no volverlos a producir en la vida real.

Siguiendo lo ya apuntado por Pilar López (2008) «de la misma forma que se aconseja para quienes trabajan en cualquier otro sector como la sanidad, la abogacía, la judicatura, el trabajo social o cualquier otro, la formación en género también es imprescindible la formación de los profesionales de los Medios de Comunicación para informar en general y para implementar adecuadamente las políticas de igualdad que se promuevan desde las diferentes Administraciones en particular» (López, 2008: 102). Y cita el documento de RTVE (2007), cuando dice que la formación es fundamental para difundir una imagen igualitaria de la mujer, que deje tras prácticas sexistas y discriminatorias, conscientes o inconscientes, fruto de siglos de educación machista, por eso considera preciso sensibilizar mediante la formación a los y las profesionales de la comunicación y a los cargos directivos de las televisiones y productoras sobre el principio de igualdad entre mujeres y hombres. También Pilar Aguilar se manifestaba en este sentido a recalcar la necesidad de la adopción de medidas «...para incentivar y favorecer por todos los medios la incorporación de mujeres a las tareas de dirección de películas. Porque... ellas equilibran la representación de nuestro mundo y la hacen menos sesgada» (Aguilar, 2015: 273), es decir, incorporan una mirada necesaria en la consecución de una sociedad más libre, una sociedad sin desigualdades entre mujeres y hombres. Y sin prejuicios asociados a la edad.

Iniciativas como las de Eurimages ${ }^{6}$ abren camino a la esperanza. Se trata de un premio del Consejo Europeo que apoya la igualdad de género y debe servir como homenaje a las mujeres cineastas. Es parte de una serie de medidas adoptadas por el Consejo Europeo para promover el equilibrio entre mujeres y hombres en la industria cinematográfica europea, tanto fuera como dentro de las pantallas. Finalmente, otro proyecto es CinAge (European Cinema for Active Ageing), un proyecto europeo Grundtvig de Aprendizaje a lo largo de la Vida que embarca a las personas mayores en un análisis crítico del cine europeo y una experiencia práctica de hacer cine, todo ello desde la base del envejecimiento activo ${ }^{7}$. En este caso, no solo es cine que incluye a mujeres mayores, sino cine hecho por mujeres mayores. Vamos avanzando.

\section{Referencias bibliográficas}

Aguilar, P. (2010). La representación de las mujeres en las películas españolas: un análisis de contenido (pp. 211-274). En F. Arranz (dir.). Cine y género en España. Madrid: Cátedra.

Aguilar, P. (2015). Desmontar relatos patriarcales y crear relatos innovadores: dos tareas imprescindibles (pp. 137-152). En T. Núñez-Domínguez, T. Vera y R. Ma Díaz (eds), La transversalidad de género en el audiovisual andaluz. Sevilla: Universidad Internacional de Andalucía.

$6 \quad$ Ver http://www.coe.int/t/dg4/eurimages/default_en.asp

7 Ver http://cinageproject.eu/en/

Revista de Evaluación de Programas y Políticas Públicas | Núm. 7 (2016), pp. 96-115 
Arango, L.G. (1998). Familia, trabajo e identidad de género (pp. 161-190). En L. Abraham y A. Abreu (org.), Gènero e trabalho na sociología Latinoamericana. Sao Paulo: Alast.

Arranz, F. (dir.) (2010). Cine y género en España. Madrid: Cátedra.

Arranz, F. (coor.) (2010). La situación de las mujeres y los hombres en el audiovisual español. Estudios sociológico y legislativo. Madrid: UCM.

Arranz, F. (2015). Aproximación al dispositivo de reproducción de las identidades de género en la literatura infantil y juvenil de ficción. En A. Hernando (ed.), Mujeres, hombres, poder. Subjetividades en conflicto. Madrid: Traficantes de Sueños.

Arrizabalaga, P. y Bruguera, M. (2009). Feminización y ejercicio de la Medicina. Médica Clínica, 133 (5), 184-186.

Burín, M. (1996). Género y Psicoanálisis: subjetividades femeninas vulnerables. En M. Burín y E.D. Bleichmar (comp.), Género, Psicoanálisis, Subjetividad. Buenos Aires: Paidós.

Carmí, M (2001). Mujeres detrás de la cámara. Madrid: Ocho y Medio.

Castejón, M. (2004). Mujeres y cine. Las fuentes cinematográficas para el avance de la historia de las mujeres. Berceo, 147, 303-327.

Castejón, M. (2012). Directoras de cine. Entre el cine de mujeres y el punto de vista de género. En M. Castejón (ed.), 25 años de cine. Muestra internacional de cine y mujeres de Pamplona. Pamplona: IPES.

Coria, C. (2003). Los laberintos del éxito. Barcelona: Paidós.

Chinchilla, N. y León, MaA A. (2004). La ambición femenina: Cómo re-conciliar trabajo y familia. Barcelona: Aguilar.

Chodorow, N (2002). Glass ceilings, sticky floors, and concrete walls: internal and external barriers to women's work and achievement (pp. 18-28). En B. Seelig, R. Paul, y C. Levy (comp.), Constructing and deconstructing woman's power. U.K: British Library.

Crenshaw, K. (1989). Demarginalizing the Intersection of Race and Sex: A Black Feminist Critique of Antidiscrimination Doctrine, Feminist Theory and Antiracist Politics. The University of Chicago Legal Forum, 1, 139-167

Delfino, A. (2005). Mujer y ejecutiva. Trayectorias de género en Brasil. Espacio Abierto, $14(2), 199-214$.

Fernández-Avilés, G. e Higueras, $M^{\mathrm{a}}$ L. (2010) ¿Cómo medir asociaciones de género en el mercado laboral? Una propuesta cualitativa para el caso español. Clm.economia, $17,57-83$.

Foster, D. W. (2001). El pacto homosocial, en convivencia de Óscar Viale. Tendencias críticas en el teatro. Buenos Aires: Galerna. 
Freixas, A. (2008). La vida de las mujeres mayores a la luz de la investigación gerontológica feminista. Anuario de Psicología, 39 (1), 41-57.

Freixas, A. (2013). Tan frescas. Mujeres maduras en el siglo XXI. Barcelona: Paidós.

García-González, A. (2009). Clases de cine. Compartir miradas en femenino y en masculino. Madrid: Instituto de la Mujer.

García-Jimenez, A.y Nuñez, S. (2008). Apuntes sobre la identidad virtual de género. Feminismos, 11, 41-58.

Gordillo, I. (2010). La mujer "envejeciente": silencios, estereotipos y miradas en el cine de la primera década del siglo XXI (pp. 97-116). En P. Sangro y J.F. Paza (eds.), La representación de las mujeres en el cine y la televisión contemporáneos. Barcelona: Laertes.

Gordillo, I. y Guarinos, V. (2010). Todos los cuerpos. El cuerpo en televisión como obsesión hipermoderna. Córdoba: Babel.

Lauzen, M. y Dozier, M.D. (1999). Making a difference in prime time: Women on screen and behind the scenes in the 1995-96 Television season. Journal of Broadcasting and Electronic Media, 43 (1), 1-19.

Lombardo, E. y Verloo, M. (2010). La interseccionalidad del género con otras desigualdades en la política de la Unión Europea. Revista Española de Ciencia Política, 23, 11-30.

López, P. (2008). Los medios y la representación de género: Algunas propuestas para avanzar. Feminismos, 11, 95-108.

Maqueira D’Angelo, V. (2002). Introducción. En V. Maqueira D’Angelo (ed.), Mujeres mayores en el siglo XXI. De la invisibilidad al protagonismo. Madrid: Ministerio de Trabajo y Asuntos Sociales.

Martínez-Salanova, E. (2003). El valor del cine para aprender y enseñar. Comunicar, 2O, 45-52.

Morduchowicz, R., Marcon, A. y Minzi, V. (2004) El cine de animación. Recuperado el 2 enero de 2016 de http://www.me.gov.ar/escuelaymedios/material/material_ cinedeanimacion.pdf.

Neroni, H. (2016). Feminist film Theory and Cléo from 5 to 7. New York: Bloomsbury Publishing.

Núñez-Domínguez, T., Estebaranz, A., Mingorance, P., Loscertales, F., y Barcia, M. (2007). Rompiendo barreras. Las personas y la organización en la empresa andaluza (pp. 71-116). En A. Estebaranz (coord.), Avanzando hacia la igualdad. Argumentos para el cambio. Sevilla: Universidad de Sevilla.

Núñez-Domínguez, T. (2010). Mujeres directoras de cine: un reto, una esperanza. PixelBit. Revista de Medios y Educación, 37, 121-133. 
Papí, N. (2003). Un nuevo paradigma para el análisis de las relaciones sociales: el enfoque de género. Feminismos, 1, 135-148.

Pinazo-Hernandis, S. (2013). Reflexionando sobre la vejez a través del cine. Una aproximación incompleta. Información psicológica, 105, 91-109.

Ramos, I. y Papí, N. (2012). Personas mayores y publicidad: Representaciones de género en televisión. Estudios sobre el mensaje periodístico, 18, 753-762.

Radio Televisión Española (2007). Televisión y políticas de igualdad. Madrid: Ministerio de Trabajo y Asuntos Sociales.

Sampedro, V. (2004) Identidades mediáticas. La lógica del régimen de visibilidad contemporánea. Sphera Pública, 4, 17-36. Citado en A. García y S. Nuñez (2008), Apuntes sobre la identidad virtual de género. Feminismos, 11, 41-58.

Silva, M. (2009). La desigualdad laboral: diagnóstico de género de la guía del audiovisual en Andalucía (pp. 117-129). En VV.AA, El audiovisual ante la ley de igualdad, Sevilla: Fundación Audiovisual de Andalucía. 